\title{
ÚLTIMAS FACES DO POETA: PROSA E POESIA DE CRUZ E SOUSA EM “ÚLTIMOS INÉDITOS”
}

\author{
Gustavo Tanus* \\ Universidade Federal de Minas Gerais
}

\begin{abstract}
As minhas rimas humildes As minhas c'roas e bravos, Que arrojarei aos das lides Da redenção dos escravos.

E nos triunfos mais brancos Dos seus litígios supernos, Lhes caiam louros, nos flancos, Os bons aplausos modernos!... (Cruz e Sousa, Aleluia).
\end{abstract}

O livro Últimos inéditos: prosa \& poesia compila textos do poeta catarinense, publicados, em sua maioria, em jornais, sob as mais variadas máscaras em diversos pseudônimos. Tal empreitada - coordenada pelo escritor e pesquisador Uelinton Farias Alves que é uma das maiores autoridades sobre a vida e a obra de Cruz e Sousa, e publicada pela Editora Nandyala - é tarefa importante para a constituição de uma documentação dos escritos concorrentes a sua obra canônica. Estes, por suplemento, deverão auxiliar os pesquisadores da poesia do poeta simbolista podendo "[...] servir de base para novos estudos, sobretudo biográficos, uma vez que a fase de juventude do poeta é ainda bastante obscura [...]" (ALVES, 2013, p. 25), concomitante ao prazer da descoberta de um outro Cruz e Sousa.

O livro reúne a produção inédita, escrita entre os anos de 1881 e 1895, dispersa em jornais e outros periódicos e que ainda não fora publicada em obra definitiva. O livro dividese em prosa e poesia inéditas, em que Cruz e Sousa apresenta sua face abolicionista e antimonárquica, em defesa da abolição da escravatura e da implantação do regime republicano, mas também revela outras faces, ocultas, muitas vezes por pseudônimos.

\section{Esta obra está licenciada sob uma Creative Commons - Atribuição 4.0}

\footnotetext{
* Bacharel em Letras/Português; bacharel em Letras/Ênfase em Edição e licenciado em Letras/Português pela Universidade Federal de Minas Gerais (UFMG), é integrante do NEIA - Núcleo de Estudos Interdisciplinares da Alteridade e colaborador do site Literafro - Portal da Literatura Afro-brasileira. E-mail: <gustavotcs@gmail.com>.
} 
Na seção dedicada à prosa, há o terceiro capítulo, ainda inédito em livro, de um possível romance nomeado "Margarida", publicado no folhetim Colombo, da cidade do Desterro - hoje, Florianópolis. Como afirma o organizador, "São traços ligeiros de um idílio sentimental, bem ao gosto do mais menoscabado romantismo, já ultrapassado [...]" (ALVES, 2013, p. 26), mas que revelam outra face do poeta em "seu projeto e do seu aprendizado como escritor". (ALVES, 2013, p. 26). As outras prosas que se seguem revelam um Cruz e Sousa ora irônico, ora sarcástico, criticando a corrupção do gênio, do caráter de figuras de seu tempo, apresentando a degeneração do político em manter a velha prática dos favores, da “algibeira", sem observar o que era indispensável à população.

Afeito aos valores humanistas, leitor de filosofia e de literatura, o poeta difunde os preceitos da Revolução Francesa, que lhes eram tão caros - a Liberdade, a Igualdade e a Fraternidade. Na crônica "A Bastilha" - homenagem ao aniversário do evento histórico - faz uma leitura da representação dessa edificação, de prisão de um Estado monarquista a símbolo da "autonomia dos verdadeiros cidadãos". (ALVES, 2013, p. 56). Em "Praia do Menino Deus", o tema é o da conservação de um bem público, melhor dizendo, um bem natural, a praia, frente ao desleixo dos políticos na inspeção, no cumprimento do dever de zelar desse patrimônio natural da cidade. E acreditando na impossibilidade de seu discurso, "[...] as chicotadas da nossa pena [...]" (ALVES, 2013, p. 58) não tocar ao poder público, o poeta delineia o papel da imprensa, de administradora do "bem estar do povo", pensamento tão urgente quanto necessário aos dias de hoje.

Em “Trancos e barrancos”, assinado pelo pseudônimo Zé K., faz-se uma crônica do que a população não espera ver nos políticos. Entretanto, de maneira prodigiosa percebe-se que esses desejos são demonstrações de práticas e condutas já existentes nos mesmos. Por sua vez "Cousas e lousas" (ALVES, 2013, p. 63-64), trata de um evento importante, a queda do gabinete Dantas, encarregado de "solucionar" o "problema" da escravidão. Cruz e Sousa critica os políticos responsáveis pelo acontecimento e o povo que não protestou. Para o poeta, o exercício do poder possui duas faces: "se uma política esbanja os cofres públicos, outra diz que não há verba e vão continuando, a despeito de tudo, as faltas e as necessidades da terra." E, dentre as necessidades, a mais importante era a libertação dos escravos.

Outros textos possuem características diferentes, mas todos parecem ter o mesmo fim: ser oposição ao conservadorismo que não permite o "progresso da terra", que deveria ser, para ele, república sem escravidão. Para isso, ele critica políticas, políticos e aqueles que, não sendo políticos, são correligionários destes. Tais textos revelam um Cruz e Sousa sem 
misericórdia com a calúnia, com as figuras de pensamentos vacilantes e de discursos claudicantes. Demonstra o vício que as instituições oficiais já mantinham, de morosidade, da falta de preocupação com aqueles para os quais elas existem. "Dr. Da Saúde, mais saúde de dever, quando se trata de saúde”. (ALVES, 2013, p. 79).

Dos 22 "Piparotes", crônicas-cascudos, contrapondo a "Voz do povo", desejosa de mudanças, com a "Noz do povo", metáfora da iniciativa do imperador de "dar nozes à quem não tem dentes" (2013, p. 87), vê-se o desejo de "[...] esvergalhar com a crítica a hipocrisia que amolece o cérebro e a religiosidade automática que cega a razão e faz abismá-la no antro da dúvida" ("Piparote 2", 2013, p. 81-82). Tratam ainda de acontecimentos rotineiros ou regionais, como festins religiosos, de uma declaração idiota feita por um local; reclama das condições deploráveis de higiene e conservação de bens públicos; faz críticas a espetáculos; trata da agenda de festas; de informação sobre recebimento de verba para uma localidade; de recebimento de livros, de periódicos de outros clubs de ideologia similar à do poeta; noticia a entrega de cartas de liberdade; o atendimento a reclamações, a inauguração de estabelecimento cultural, os atos administrativos sem propósitos, entre outros. Mas aborda grandes questões de seu tempo, como a indenização que os "possuidores de escravos" receberiam, após a abolição: "E quem indenizou os míseros escravos da sua eterna noite de treva, das suas agonias, das suas aflições, das suas lágrimas?!” (ALVES, 2013, p. 87).

$\mathrm{Na}$ seção "Outros textos", os escritos parecem mais ensaísticos, exposição mais desenvolvida, mais literária de temas como: instrução pública, em que trata da educação naquilo como se dá e como deveria ser; a chegada da primavera ou mesmo a estação de colheita, do renascimento da natureza em cores diversas em relação ao olhar atormentado do homem ou apenas visão otimista sobre a natureza; sobre as crianças, em que é lançado um olhar nostálgico sobre a infância, sua educação, sua generosidade, em relação ao "doloroso e pungente pessimismo humano" de seu mestre; casas, em que debate a questão da luta da população por moradia pela elevação dos preços dos aluguéis; ainda, críticas de mais fôlego a outros escritores e obras; a vida; o sol; o amor etc. Cores, sabores, ecos, ritmos, sons, expressão poética e artística. Com escritos menos cáusticos e irônicos, menos sarcásticos ou zombeteiros, esta seção possui textos mais fluidos, menos tensos porque o "cálculo" da expressão é outro.

A segunda parte do livro é composta dos versos do poeta que, por algum motivo, não 
constam de sua obra poética publicada nos $\operatorname{livros}^{1}$. Tais versos se agrupam em formas poéticas diversas e variados temas. Ademais da temática incomum do poema "Ao jantar", vale destacar a sonoridade dos seus tercetos: “[...] Que foi? Foi a faca, má, está cotó / Que o dedo me cortou sem pena e dó / Resvalando da mão, no chão, certeira. / Fiquei triste e... a barriga descontente / O apetite perdeu neste incidente / Passando sem comer a tarde inteira!..." (2013, p. 224). Em relação à versificação ou aos recursos estilísticos, há versos brancos como em “Cabriolas" (2013, p. 232), em que a voz poética faz uma crítica à postura pela indumentária burguesa; ou versos que exploram os ecos, como em "Fiáus", onze poemas em uma crítica ao baronato, findando com os triolés que foram alocados em uma subseção conforme a tipologia da composição. ${ }^{2}$ Tal modalidade representa, segundo Uelinton Farias Alves, um período da produção poética de Cruz e Sousa, e vai desaparecendo de sua expressão "até a cristalização de seu estilo, que vai culminar na obra imortal, que são suas produções simbolistas. (ALVES, 2013, p. 20). Destes triolés, "Questão dupla" sobressai-se por tratar do conflito do gari frente a sua missão "questão do lixo" como matéria de seu trabalho e a "questão da carne", que é sua sobrevivência. Dessa temática de fazer durar a carne, o corpo, pela subsistência, aliam-se os poemas "Mais pão", "Carne... por um óculo" e "O bife".

Vale destacar, aqui, os dois poemas que tratam mais diretamente da questão da escravidão e do abolicionismo. São eles, o soneto "Nova realeza" e o de versos em heptassílabos, "Aleluia!”. O primeiro faz saber da nova realeza, que surge, impondo-se como a lei e ensinando como a escola, e "[...] que sabe castigar os frutos do pecado; / do Olimpo desabando os deuses mentirosos [...]" (ALVES, 2013, p. 220), que sendo improrrogável, será implacável, e chama-se Liberdade. O outro poema, dedicado à estréia do Club Abolicionista "Ceará Livre", prenuncia que, após longa odisseia entremeada de aventuras e desventuras, a nau avista o farol da liberdade. Novos tempos, nova era, “[...] que sepulta os erros nas lousas", tempos modernos em que as rimas, embora humildes, a que receberão coroas e bravos, serão alinhadas aos das lutas na demanda da libertação dos escravos, e, no fim, a estes bravos deverão cair louros em coroação da vitória pela abolição.

Por fim, apresentados alguns fios destes tecidos, nas prosas e nos versos inéditos, pelas “[...] máscaras de Zat, Zot, Zut, Cruz, Trac, Coriolano Scevola, Zé K. e Lord” (ALVES,

\footnotetext{
${ }^{1}$ SOUSA, Cruz e. Missal. Rio de Janeiro: Magalhães \& Cia., 1893. SOUSA, Cruz e. Broquéis. Rio de Janeiro: Magalhães \& Cia., 1893. SOUSA, Cruz e. Evocações. Rio de Janeiro: Tipografia Aldina, 1898. SOUSA, Cruz e. Faróis. Rio de Janeiro: Tipografia Instituto Profissional, 1900. SOUSA, Cruz e. Últimos sonetos. Paris: Aillaud \& $\mathrm{Cia}, 1905$.

${ }^{2}$ Triolés são um tipo de composição poética configurada em estrofes de oito versos, em que o primeiro, o quarto e o sétimo versos se repetem e o oitavo é igual ao segundo, na sequência: ABCADEAB.
} 
2013, p. 18), são reveladas outras faces do poeta. Ele que, pela voz do amigo Oscar Ribas, foi desterrado "por ter mais competência que seus competidores" (ALVES, 2013, p. 34). De trágica sina, Cruz e Sousa aguardou várias décadas até a apresentação destes seus últimos inéditos: um livro valioso para quem se inclina à prosa e à poesia, mais ainda, para quem aprecia um dos maiores escritores brasileiros, em válida e merecida homenagem realizada por Uelinton Farias Alves.

\section{Referência}

ALVES, Uelinton Farias (Coord.). Últimos inéditos: prosa \& poesia. Belo Horizonte: Nandyala, 2013.

[Recebido em outubro de 2015 e aceito para publicação em outubro de 2015]

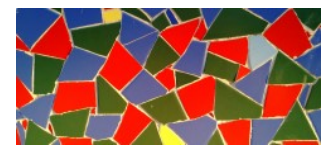

